\title{
Protein Malnutrition and the Febrile Response in the Fischer Rat
}

\author{
Suzanne F. Bradley and Carol A. Kauffman \\ Division of Infectious Diseases, Department of Internal Medicine, VA Medical Center and \\ University of Michigan Medical School, Ann Arbor
}

\begin{abstract}
We assessed the effect of protein deprivation on the ability of peritoneal macrophages from Fischer rats to produce interleukin-1 (IL-1) after in vitro stimulation. Pyrogenic activity of supernatants was measured by an in vivo febrile response assay. Control rats were given a $23 \%$ casein diet and protein-malnourished rats were given an $8 \%$ casein diet for 4 weeks. IL-1-containing supernatants prepared from peritoneal macrophages were injected into assay rats, whose temperatures were measured for 6 hours $\left(\Delta T_{6}\right)$. Rats injected with IL-1-containing supernatants derived from peritoneal macrophage cultures of protein-deprived rats had significantly less fever $\left(\Delta T_{6}=0.20 \pm 0.09^{\circ} \mathrm{C}\right)$ than rats injected with IL-1 containing supernatants derived from peritoneal macrophage cultures of control rats $\left(\Delta \mathrm{T}_{6}=0.56 \pm 0.09^{\circ} \mathrm{C}\right), P<.01$. Protein mainutrition leads to diminished pyrogenicity of macrophage culture supernatants and may be at least partly responsible for the decreased febrile response seen in the malnourished animals.
\end{abstract}

Key words: interleukin-1, fever, peritoneal macrophage, nutrition

\section{INTRODUCTION}

Protein deprivation has been shown to cause hypothermia, depressed cell-mediated immunity, and changes in macrophage function, which may contribute to a diminished ability to fight infection in the malnourished state $[2,4,14,21]$. A decrease in fever, an important nonspecific host defense mechanism, has been reported in protein-deprived animals [8] and in malnourished humans with various infections [19]. This decreased febrile response could be related to decreased production of or decreased responsiveness to interleukin-1 (IL-1), a protein that mediates the febrile response [5]. Previously, we found that monocytes from protein-malnourished patients have a diminished ability to produce IL-1 [12]. Little has been done in this area using animal models of protein malnutrition, but there is evidence that rabbits that are protein malnourished may have decreased IL-1 production [8]. We have noted that protein-deprived Fischer rats show a diminished febrile response to endotoxin suggesting the possibility that they may not produce normal amounts of IL-1 in response to a pyrogenic stimulus [3]. In this study, we examined the responses of peritoneal macrophages from protein-malnourished rats to in vitro stimulation with production and release of an IL-1-like substance.

\section{MATERIALS AND METHODS}

\section{Animals and Diet}

Two-month-old male Fischer 344 rats (Harlan Industries, Indianapolis) were housed individually in wire mesh cages in a 12-hour light-dark photoperiod and at an ambient temperature of $26 \pm 1^{\circ} \mathrm{C}$. Each rat was fed either the control diet, 23\% casein, number 5001 (Ralston Purina, Inc., St. Louis) or an isocaloric $8 \%$ casein diet (ICN Biochemicals, Inc., Cleveland) ad libitum for 4 weeks. The major components and kilocalories contained in each diet have been described previously [3]. Actual food intake was measured daily, and body weights were recorded weekly. A greater number of protein-deprived animals $(n=36)$ were used when compared with controls $(n=18)$ since preliminary studies showed lower yields of peritoneal macrophages in protein-malnourished rats.

\section{IL-1 Production}

IL-1-containing supernatants were obtained from peritoneal macrophages harvested from rats in the beginning

Received May 20, 1987; accepted June 26, 1987.

Reprint requests: Suzanne F. Bradley, Infectious Disease Section, Veterans Administration Medical Center, Ann Arbor, MI 48105. 
of the 5th week of the experiment. Rats were injected intraperitoneally with $30 \mathrm{ml}$ of shellfish glycogen (Sigma, Inc., St. Louis) which had been dissolved in $0.9 \% \mathrm{NaCl}$ to give a concentration of $0.2 \mathrm{~g} / \mathrm{dl}$. Seventy-two hours later, the rats were anesthetized with methoxyfluorane and exsanguinated by cardiac puncture. Macrophages were obtained by washing the peritoneal cavity with $\mathbf{5 0}$ ml Hanks' balanced salt solution (HBSS) to which was added $1 \mathrm{unit} / \mathrm{ml}$ of heparin (Lypho Med, Inc., Melrose, IL). The cells were centrifuged, washed twice with HBSS and resuspended to a concentration of $2.5 \times 10^{6}$ macrophages $/ \mathrm{ml}$. Rats whose wash yielded less than $3 \mathrm{ml}$ of cell suspension were excluded. Macrophage preparations were mixed for 1 hour at $37^{\circ} \mathrm{C}$ with heat-killed Staphylococcus epidermidis (20:1 bacteria/macrophage) and $10 \%$ human serum. The cells were then washed and incubated for 18 hours in a $5 \% \mathrm{CO}_{2}$ atmosphere at $37^{\circ} \mathrm{C}$. Supernatants were collected and stored at $-70^{\circ} \mathrm{C}$ prior to use.

\section{Febrile Response Assay}

The pyrogenic activity of each supernatant was assessed by measuring the febrile response obtained in 3month-old Fischer 344 male rats maintained on a control diet. Body temperature in this assay group was measured by battery-operated biotelemetry devices (Mini-Mitter, Inc., Sun River, OR) implanted intraperitoneally into each rat 5 days before the febrile response study was performed. Output from each transmitter was proportional to body temperature. Changes in the transmitter signal were monitored by an AM radio receiver held outside the cage as previously described [23].

First, $1.5 \mathrm{ml}$ of supernatant containing IL-1 (the amount obtained from $3.75 \times 10^{6}$ macrophages) from each rat was injected intraperitoneally into two or three different assay rats; the yield from some rats was not enough to perform the assay in triplicate, and those were performed in duplicate only. Supernatant containing IL-1 from different rats were not pooled together. HBSS $(1.5 \mathrm{ml})$ was injected intraperitoneally into assay rats as a control.

Body temperature was measured three times in the hour preceding injection of supernatants or HBSS, and the mean of the three readings was used as a baseline temperature. All measurements were done at the same time of the day, with injection occurring between 8:30 and 9:30 AM. Following injection, body temperature was recorded every 30 minutes for 6 hours.

Results were expressed as change in temperature from baseline at each time point. The mean response of the triplicate or duplicate assays run on each different IL-1 preparation was determined. Change in temperature for each time point and the change in temperature over the entire 6-hour experiment $\left(\Delta \mathrm{T}_{6}\right)$ were expressed as the mean \pm S.E.M.

\section{IL-1 Inactivation}

A further experiment was done in which the macrophage supernatants from six different control rats were heated in a $70^{\circ} \mathrm{C}$ water bath for 30 minutes and then injected into a different group of assay rats. IL-1 activity is abolished by 30 minutes at this temperature, while other pyrogens, such as tumor necrosis factor (TNF) and endotoxin require higher temperatures or a longer period of heating to become inactivated [6]. Additionally, these supernatants, both unheated and heated, were used in a standard thymocyte stimulation assay for lymphocyteactivating factor (LAF) activity of IL-1 [16]

\section{Assay for Protein Malnutrition}

After peritoneal macrophages were harvested, the liver was removed and stored at $-70^{\circ} \mathrm{C}$ for determination of L-alanine aminotransferase (ALT) activity, a marker of protein malnutrition [7]. ALT activity was measured using an assay for NADH oxidation (Sigma, Inc.). Results were expressed as $\mu \mathrm{mol} \mathrm{NAD} / \mathrm{min} / \mathrm{mg}$ protein. Liver protein content was measured using a modified Lowry assay [15].

\section{Statistical Methods}

Differences between the febrile responses to IL-1 obtained from control and protein-malnourished rats and between the febrile responses to IL-1 from both groups and HBSS were compared using Student's t-test. Differences between protein malnourished and control rats in regard to weight, liver ALT activity, and peritoneal macrophage yield also were compared using Student's t-test.

TABLE 1. Effect of Low-Protein Diet on Weight Gain, Liver ALT Activity, and Peritoneal Macrophage Yield ${ }^{\mathrm{a}}$

\begin{tabular}{lccc} 
& Control diet & Low-protein diet & $P$-value \\
\hline Weight gain in 4 weeks $(\mathrm{g})$ & $62.3 \pm 2.5$ & $8.3 \pm 1.1$ & $<.0005$ \\
$\begin{array}{l}\text { Liver ALT activity } \\
\quad(\mu \mathrm{mol} \text { NAD/min/mg protein) }\end{array}$ & $1.1 \pm 0.1$ & $0.5 \pm 0.1$ & $<.005$ \\
$\begin{array}{l}\text { Peritoneal macrophage yield } \\
\left(\text { cells/ml } \times 10^{6}\right)\end{array}$ & $2.3 \pm 0.4$ & $1.2 \pm 0.2$ & $<.005$ \\
\hline
\end{tabular}

${ }^{\mathrm{a} A L T}=\mathrm{L}$-alanine aminotransferase. Data are expressed as mean $\pm \mathrm{SEM}$. 


\section{RESULTS}

The effects of the low-protein diet on weight gain, liver ALT activity, and macrophage yield are shown in Table 1. Protein-deprived rats gained significantly less weight than controls over the 4-week period of the study; they consumed less food and fewer kilocalories per day than the controls (mean $\mathrm{kcal} / \mathrm{d}$ was $78.5 \pm 1.5$ for the controls vs. $59.3 \pm 4.2$ for the low-protein diet, $P<$ .0005). L-alanine aminotransferase activity was significantly reduced in the experimental diet group, confirming these animals to be protein malnourished. The yield of peritoneal macrophages was almost twice as great in the control rats as in the protein-malnourished rats $(P<$ $.005)$.

Assay rats injected with IL-1-containing supernatants from peritoneal macrophage cultures of protein-malnourished rats had a significantly diminished febrile response when compared with those rats given IL-1-containing supernatants from peritoneal macrophage cultures of well-nourished rats (Fig.1). The febrile response to IL1-containing supernatants derived from protein-malnourished rats expressed as $\Delta \mathrm{T}_{6}$ was $0.20 \pm 0.07$, while the febrile response to IL-1-containing supernatants from control rats was $0.56 \pm 0.05(P<.01)$. The response to HBSS was significantly different from the response to IL-1-containing supernatant derived from control rats $(P$ $<.0005$ ) but not different from the response to IL-1containing supernatants from protein-malnourished rats $(P=.17)$.

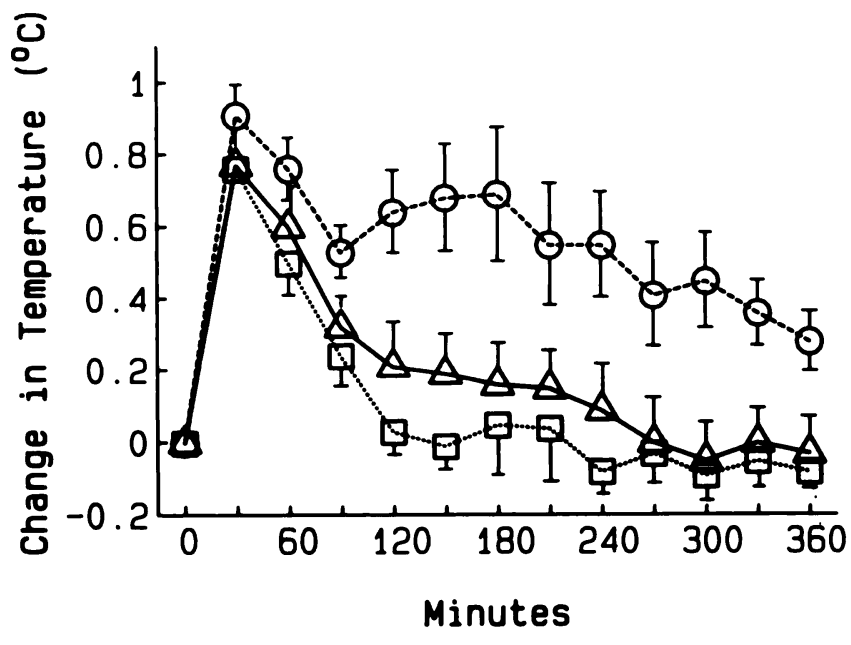

Fig. 1. Febrile responses of assay rats following injection with IL-1-containing supernatants from peritoneal macrophage cultures of control rats $(n=11)(O)$, IL-1-containing supernatants from peritoneal macrophage cultures of protein-malnourished rats $(n=17)(\triangle)$, or Hanks' balanced salt solution $(n=20)$ (口). Prior to injection, baseline temperatures were similar for all groups, ranging from $36.8^{\circ} \mathrm{C}$ to $37.0^{\circ} \mathrm{C}$. The response to IL1 containing supernatants from control rats was significantly greater than that from protein-malnourished rats, $P<.01$.
TABLE 2. ${ }^{3} \mathrm{H}$-Thymidine Incorporation by Thymocytes in Response to IL-1*

\begin{tabular}{lr}
\hline & DPM \pm SEM \\
\hline Unstimulated & $124 \pm 27$ \\
PHA & $1,034 \pm 106$ \\
PHA + IL-1 & $3,422 \pm 549$ \\
PHA + heated IL-1 & $877 \pm 99$ \\
\hline
\end{tabular}

${ }^{\text {a DPM }}=$ disintegrations per minute; PHA dose $=5 \mu \mathrm{g} / \mathrm{well}$; IL-1 dose/well $=$ amount from $2.5 \times 10^{3}$ macrophages.

${ }^{b}$ Heated at $70^{\circ} \mathrm{C}$ for 30 minutes.

Supernatants heated to $70^{\circ} \mathrm{C}$ for 30 minutes were rendered nonpyrogenic $\left(\Delta \mathrm{T}_{6}=0.06 \pm 0.05\right)$ which made it likely that IL-1, and not TNF or endotoxin contamination, was responsible for the pyrogenicity of the macrophage supernatants. In addition, unheated supernatants showed LAF activity, and heating the supernatants to $70^{\circ} \mathrm{C}$ for 30 minutes abolished the LAF activity (Table 2).

\section{DISCUSSION}

Although it has been noted that malnourished patients have a diminished febrile response, the mechanism for this defect is unknown. The ability of these patients to produce or secrete IL-1 has been evaluated in only a few instances $[9,12,13]$. Hoffman-Goetz et al. showed that IL-1-containing supernatants harvested from monocytes of patients with kwashiorkor (predominantly protein malnutrition) produced little fever and no significant change in plasma iron when injected into rabbits; in comparison, IL-1-containing supernatants from monocytes of patients with marasmus (predominantly caloric malnutrition) produced normal febrile and plasma iron responses in rabbits [9]. These results suggested that protein deprivation had a greater effect on decreasing IL-1 production than did caloric restriction. Following nutritional replacement, IL1 production returned to normal in protein-deprived patients [9]. Studies in our laboratory and those of Keenan et al, which used different assays for IL-1 activity in the intact animal, have noted decreased production or secretion of IL-1 by monocytes of chronically ill and acutely ill malnourished patients, respectively $[12,13]$.

We have used a Fischer rat model to explore further the role of protein malnutrition on the febrile response. Initial studies revealed that protein-malnourished rats in several different age groups had a diminished febrile response to endotoxin, suggesting the possibility of a defect in their ability to make or to release IL-1 [3]. In addition, protein-malnourished rats showed a decrease in their febrile response when IL-1 containing supernatants from human monocyte cultures were infused, suggesting an additional defect in the thermoeffector limb of the protein-malnourished rat. 
The current experiments looked more closely at the effects of mild-to-moderate protein malnutrition on peritoneal macrophage IL-1 production. A significant decrease in pyrogenic effect was noted when supernatants of cultures of peritoneal macrophages from protein-malnourished rats were injected into assay animals. The febrile response elicited by these supernatants was no greater than that seen with injection of nonpyrogenic HBSS.

Crude macrophage supernatants, rather than purified IL-1 preparations, were used in these experiments because we felt it important to test individual rats and not to pool cell preparations. The cell yield was too low, especially from protein-malnourished animals, to undertake purification of the supernatants and still carry out a febrile response assay in several assay rats. It is possible that the crude supernatants contained other pyrogenic substances produced by macrophages, such as TNF $[1,18]$. This substance, produced by stimulated macrophages in culture, shares with IL-1 the effect of producing fever in rabbits (and presumably rats) but differs from IL-1 in that it does not cause thymocyte proliferation $[1,18]$.

However, the experiments involving obliteration of the febrile response with heated supernatants make it appear unlikely that TNF was contributing to the febrile response induced by the macrophage supernatants. TNF is more heat-stable than IL-1, and its activity is not abolished by heating to $70^{\circ} \mathrm{C}$ [6]. In addition, our crude macrophage supernatants contained IL-1 activity when used in a LAF assay of thymocyte stimulation, an activity that IL-1 does not share with TNF. When these same supernatants were heated to $70^{\circ} \mathrm{C}$ for 30 minutes, the IL1 activity in the LAF assay was abolished. Further proof that IL-1 alone was responsible for the pyrogenic activity could be sought by abolishing the febrile response with anti-rat-IL-1 antibody. However, this awaits further purification of rat IL-1 and production of specific antibody.

The number of macrophages elicited by shellfish glycogen stimulation of the peritoneum was diminished in protein-malnourished rats; the yield was almost twice as high in the control rats. A decrease in the number of elicited peritoneal macrophages has been noted previously in protein-malnourished animals $[10,20]$. Since we corrected for the number of macrophages in each cell preparation, the decreased cell yield in the protein-malnourished animals did not contribute to the diminished IL-1 activity.

Rats on the low-protein diet ate less food than those on the control diet so that caloric intake was also less in this group. It is possible that the combination of protein and calorie restriction acted synergistically to decrease the IL-1 output from peritoneal macrophages of these ani- mals. In clinical studies reported to date, both protein and caloric malnutrition were present, and the combination clearly is very common in hospitalized patients $[12,13]$.

Hoffman-Goetz has used a rabbit model of protein deprivation to look at the question of IL-1 production and its effect on the febrile response. She found that proteinmalnourished rabbits showed an attenuated febrile response to infection with Pasturella multocida, and in further studies in a few rabbits, she found that the diminished febrile response was related to decreased IL-1 synthesis [8]. She noted a normal febrile response in proteinmalnourished rabbits given IL-1-containing supernatants prepared from control rabbits. In contrast, as noted above, our studies in Fischer rats have shown that both the affector limb (production or secretion of IL-1) and the effector limb (peripheral thermoeffector responses to IL-1) were influenced adversely by protein malnutrition [3].

In the protein-malnourished pateint, the return of cellmediated immunity, macrophage function, and perhaps IL-1 production may be brought about by intensive nutritional replacement [22]. It has been postulated that IL-1 supplementation could prove beneficial in fighting infection [17]. However, infusion of a substance that might increase acute phase reactants, cause muscle breakdown, and have other side effects has to be questioned. Kampschmidt et al, addressed the question of whether IL-1 supplementation might have a beneficial role in host defense. In that study, IL-1-containing crude macrophage supernatants given to rats 24 hours prior to infection with Salmonella typhimurium were protective against lethal infection [11]. Whether IL-1 supplementation would be even more beneficial in protein-malnourished rats unable to make adeqate amounts of IL-1 has not been assessed. Further work with both crude IL-1 and further purified and recombinant IL-1 should be pursued to assess the role of IL-1 in infection occurring in the protein-malnourished state.

\section{ACKNOWLEDGMENTS}

This study was supported by the Veterans Administration Research Service.

\section{REFERENCES}

1. Beutler, B., Mahoney, J., LeTrang, N., Pekala, P., Cerami A. Purification of cachectin, a lipoprotein lipase-suppressing hormone, secreted by endotoxin-induced RAW 264.7 cells. J. Exp. Med. 161,984, 1985.

2. Bistrian, B.R., Blackburn, G.L., Scrimshaw, N.S., and Flatt, J.P. Cellular immunity in semistarved states in hospitalized adults. Am. J. Clin. Nutr. 28,1148, 1975. 
3. Bradley, S.F., Kluger, M.J., Kauffman, C.A. Age and protein malnutrition: Effects on the febrile response. Gerontology 33,99, 1987.

4. Brenton, D.P., Brown R.E., and Wharton, B.A. Hypothermia in kwashiorkor. Lancet 1,410, 1967.

5. Dinarello, C.A. Interleukin-1. Rev. Infect. Dis. 6,51, 1984.

6. Dinarello, C.A., Cannon, J.G., Wolff, S.M., Bernheim, H., Beutler, B., Cerami, A., Figari, I.S., Palladino, M.A., and O'Connor, J.V. Tumor necrosis factor (cachectin) is an endogenous pyrogen and induces production of interleukin-1. J. Exp. Med. 163,1433, 1986.

7. Heard, C.R.C., Frangi, S.M., and Wright, P.M. Biochemical characteristics of different forms of protein-energymalnutrition: An experimental model using young rats. Br. J. Nutr. 37,1, 1977.

8. Hoffman-Goetz, L., and Kluger, M.J. Protein deprivation: Its effects on fever and plasma iron during bacterial infection in rabbits. J. Physiol. (London) 295,419, 1979.

9. Hoffman-Goetz, L., McFarlane, D., Bistrian, B.R. and Blackburn, G.L. Febrile and plasma iron responses of rabbits injected with endogenous pyrogen from malnourished patients. Am. J. Clin. Nutr. 34,1109, 1981.

10. Iyengar, U.R., and Vakil, U.K. Enumeration and structural assessment of peritoneal macrophages during progressive protein deficiency in rats. J. Biosci. 7,15, 1985.

11. Kampschmidt, R.F., and Pulliam, L.A. Stimulation of antimicrobial activity in the rat with leukocyte endogenous mediator. J. Reticuloendothel. Soc. 17, 162, 1975.

12. Kauffman, C.A., Jones, P.G., and Kluger, M.J. Fever and malnutrition: Endogenous pyrogen/IL-1 production in malnourished patients. Am. J. Clin. Nutr. 44,449, 1986.

13. Keenan, R.A., Moldawer, L.L., Yang, R.D., Kawamura, I., Blackburn, G.L., and Bistrian, B.R. An altered response by peripheral leukocytes to synthesize or release leukocyte endoge- nous mediator in critically ill protein malnourished patients. J. Lab. Clin. Med. 100,844, 1982.

14. Keusch, G.T., Douglas, S.D., Braden, K., and Geller, S.A. Antibacterial functions of macrophages in experimental proteincalorie malnutrition. J. Infect. Dis. 138, 125, 1978.

15. Lowry, D.H., Rosebrough, N.J., Farr, A.L., and Randall R.J. Protein measurement with the Folin phenol reagent. J. Biol. Chem. 193, 265, 1951.

16. Mizel, S.B., Oppenheim, J.J., and Rosenstreich, D.L. Characterization of lymphocyte-activating factor (LAF) produced by the macrophage cell line P388D. J. Immunol. 120,1497, 1978.

17. Moldawer, L.L., Sobrado, J., Blackburn, G.L. and Bistrian, B.R. A rationale for administering leukocyte endogenous pyrogen mediator to protein malnourished, hospitalized patients. J. Theor. Biol. 106,119, 1984.

18. Nathan, C.F., Secretory products of macrophages. J. Clin. Invest. 79, 319, 1987.

19. Phillips, I., and Wharton, B. Acute bacterial infection in kwashiorkor and marasmus. Br. Med. J. 1,407, 1968.

20. Price, P., and Bell, R.G. The toxicity of inactivated bacteria and endotoxin in mice suffering from protein malnutrition. J. Reticuloendothel. Soc. 18,230. 1975.

21. Smythe, P.M., Schonland, M., Brereton-Stiles, G.G., Coovadia, H.M., Grace H.J., Leoning, W.E.K., Mafoyane, A., Parent, M.A., and Vos, G.H. Thymolymphatic deficiency and depression of cell-mediated immunity in protein calorie malnutrition. Lancet 2,939, 1971.

22. Tayek, J.A., and Blackburn, G.L. Goals of nutritional support in acute infections. Am. J. Med. 76, 81, 1984.

23. Tocco-Bradley, R., Kluger, M.J., and Kauffman, C.A. Effects of age on fever and acute-phase response of rats to endotoxin and Salmonella typhimurium. Infect. Immun. 47,106.1985. 